\title{
Perencanaan Kebutuhan Pranata Laboratorium Pendidikan di Institut Pertanian Bogor
}

\author{
( Requitment Planning of Laboratory Education Staff \\ at Bogor Agricultural University)
}

\author{
Eko Prasetyo ${ }^{1}$, M. Syamsul Maarif ${ }^{2}$, dan Komar Sutriah ${ }^{3}$ \\ abiprastyo@gmail.com \\ ${ }^{1}$ Mahasiswa Program Pascasarjana Manajemen dan Bisnis IPB (MB-IPB) \\ ${ }^{2}$ Program Pacasarjana Manajemen dan Bisnis IPB (MB-IPB) \\ ${ }^{3}$ Kepala Laboratorium Terpadu IPB/Dosen Departemen Kimia
} FMIPA-IPB

\begin{abstract}
The objective of the research was to analyze requirement planning, ideal number as well as formulating planning strategy for Laboratory Education Staff (LES) at Bogor Agricultural University. Data was collected by filling the questionnaire and interview with laboratory staff of Bogor Agricultural University, then documentation. Completely randomized design and Antilon (anti-In/ $e^{\text {nilai } y}$ ) was performed to analyze the data, then geometric mean value was analysed by qualitative descriptive, whereas formulation of strategy was performed by SWOT matric.

The result shows that time activities allocation by LES were still low as well as less ideal number of LES. In addition, according to SWOT matric analysis, formulation of the strategies to improve work quality of LES were development of staff capability, providing adequate tools and materials, escalating of staff performance and refinement of leadership manner.
\end{abstract}

keywords : LES, laboratory, strategy

\begin{abstract}
ABSTRAK
Penelitian ini bertujuan untuk menganalisis perencanaan kebutuhan dari pranata labaroratorium pendidikan (PLP) dan jumlah ideal serta merumuskan strategi perencanaan kebutuhan pranata laboratorium pendidikan di Institut Pertanian Bogor. Jenis penelitian adalah deskriptif kualitatif, Data dikumpulkan melalui penyebaran kuisoner butir kegiatan kepada seluruh PLP di IPB, wawancara dan dokumentasi. Data dianalisis dengan beberapa tahapan, yaitu data dianalisis dengan cara analisa ragam (ANOVA) dan rancangan yag digunakan yaitu Rancangan Acak Lengkap (RAL) nilai yang diperoleh selanjutnya dilakukan antilon (anti-ln/ $/ \mathrm{e}^{\text {nilai }}{ }^{\mathrm{y}}$ ), maka akan mucul rataan geometrik kemudian dianalisis secara deskriptif kualitatif dan perumusan strategi dengan matrik SWOT. Hasil penelitian menunjukan bahwa masih sedikitnya curahan waktu kegiatan yang dilakukan PLP, jumlah PLP yang belum ideal dan berdasarkan analisis matrik SWOT, strategi yang dirumuskan peningkatan kualiatas kerja PLP yaitu mengembangkan kapabilitas, menyediakan peralatan dan bahan sesuai kebutuhan, meningkatnya kinerja PLP serta memperbaiki gaya kepemimpinan.
\end{abstract}


Kata kunci : PLP, laboratorium dan Strategi

\section{PENDAHULUAN}

Laboratorium memegang peranan penting dan strategis dalam mendukung kegiatan akademik di perguruan tinggi yang merupakan sarana bagi mahasiswa dan dosen dalam melakukan kegiatan pendidikan, penelitian, dan pengabdian kepada masyarakat PERMENRISTEKDIKTI No. 44 tahun 2015 tentang Standar Nasional Pendidikan Tinggi (SNPT). Laboratorium perguruan tinggi harus dikelola oleh tenaga kependidikan Pranata Laboratorium Pendidikan secara profesional agar fungsi laboratorium terhadap kegiatan tridharma perguruan tinggi dapat maksimal sesuai dengan fungsi keberadaan laboratorium tersebut.

Pada awal tahun 2010, berdasarkan Peraturan Menteri Negara Pendayagunaan Aparatur Negara dan Reformasi Birokrasi No. 03/Januari/2010 dan Peraturan Bersama Menteri Pendidikan Nasional dan Kepala Badan Kepegawaian Negara No. 02/V/PB/2010 dan No. 13/Mei/2010, telah mulai menerapkan jabatan fungsional pada teknisi, laboran, analis dan instruktur yang sekarang dikenal dengan nama Pranata Laboratorium Pendidikan (PLP). PLP merupakan jabatan yang mempunyai ruang lingkup tugas, tanggung jawab, dan wewenang untuk melakukan pengelolaan laboratorium pendidikan yang diduduki oleh Pegawai Negeri Sipil (PNS) dengan hak dan kewajiban yang diberikan secara penuh oleh pejabat yang berwenang. PLP memiliki ruang lingkup tugas mengelola laboratorium berdasarkan metode keilmuan tertentu, baik untuk pendidikan, penelitian dan pengabdian kepada masyarakat.

Kebijakan ini ditetapkan pemerintah untuk mengatasi masalah terbatasnya pengembangan karir instruktur, laboran dan teknisi serta memberikan kesempatan untuk melanjutkan pendidikan ke jenjang yang lebih tinggi sesuai dengan bidang tugas yang diembannya sehingga kinerja PLP diharapkan akan meningkat seiring dengan motivasi yang tumbuh karena adanya penghargaan terhadap profesionalisme PLP tersebut.

Institut Pertanian Bogor (IPB) sebagai sebuah institusi pendidikan sangat perlu melakukan perencanaan sumberdaya manusia terutama sejak dicanangkannya IPB sebagai Research Based University, yang salah satu tujuannya adalah untuk meningkatkan kualitas output riset yang mau tak mau melibatkan berbagai laboratorium di IPB. Oleh karena itu, perencanaan PLP yang mendukung performa laboratorium dalam pencapaian visi dan misi tersebut sangat dibutuhkan. Menurut Wirawan (2009) dalam pencapaian visi dan misinya, setiap organisasi memerlukan sumberdaya yang merupakan sumber energi, tenaga, dan kekuatan yang diperlukan untuk menciptakan daya gerakan, aktifitas, kegiatan dan tindakan. Disamping itu, seperti yang terdapat dalam Renstra IPB 2014-2018 bahwa pengelolaan dan pengembangan sumber daya manusia masih merupakan kelemahan internal sehingga dalam mencapai visi dan misinya IPB dituntut untuk secara terus menerus meningkatkan kualitas dan kuantitas SDM. Perencanaan kebutuhan akan laboratorium yang terstandarisasi, PLP yang kompeten (ISO/IEC 17025:2005) dan kesesuaian antara tipe laboratorium dan kompetensi yang dimiliki PLP menjadi hal yang krusial untuk dilakukan oleh IPB saat ini.

Eko Prasetyo, M Syamsul Maarif, dan Komar Sutriah 
Berdasarkan data Direktorat SDM IPB tahun 2014 dari 1654 tenaga kependidikan (non dosen) yang dimiliki, yang didalamnya terdapat 161 orang tenaga PLP yang telah di inpassing atau disesuaikan dalam jabatan fungsional pranata laboratorium pendidikan (PLP) dan tersebar ke dalam 187 jenis laboratorium. Gambar berikut memperlihatkan sebaran PLP menurut Fakultas dan kantor pada laboratorium yang ada di IPB.

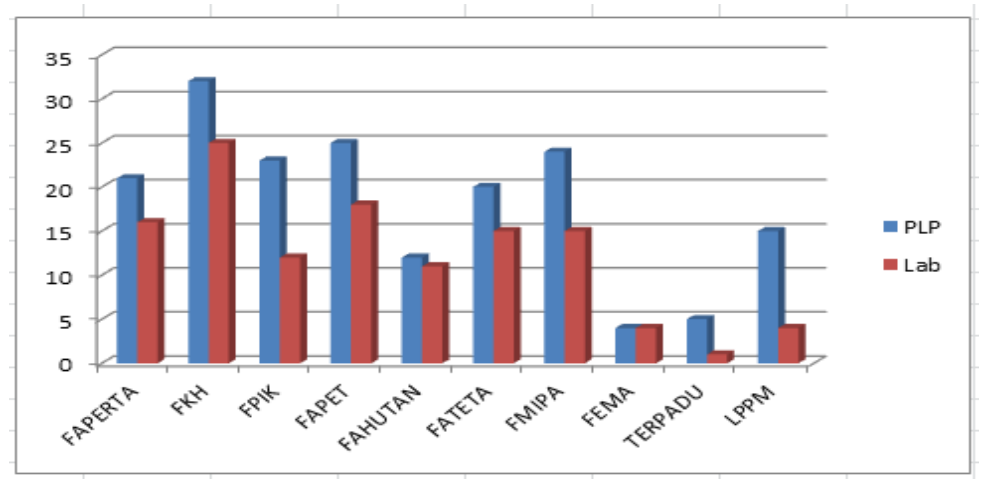

Sumber : Direktorat SDM

Gambar 1 Sebaran PLP menurut fakultas dan kantor pada laboratorium IPB

Penelitian mengenai Perencanaan kebutuhan PLP, bertujuan untuk menganalisis perencanaan formasi beban kerja PLP yang mengacu pada PERMENPAN\&RB serta merekomdasikan Strategi dalam merumuskan perencanaan kebutuhan PLP di IPB, guna meningkatkan produktivitas kerja laboratorium dan untuk mendukung pencapaianpencapaian tujuan yang telah ditetapkan oleh IPB sebagai world class university.

\section{METODOLOGI}

\section{Tempat dan Waktu}

Penelitian ini dilaksanakan di IPB. Pemilihan lokasi sebagai tempat penelitian dilakukan secara sengaja (purposive), dengan pertimbangan bahwa IPB telah menerapkan jabatan fungsional PLP yang ditetapkan oleh pemerintah. Penelitian ini dilakukan mulai bulan Maret sampai dengan bulan Desember tahun 2015

Jenis Penelitian ini bersifat deskriptif dengan pendekatan kualitatif. Pranata laboratorium Pendidikan IPB ditetapkan sebagai obyek penelitian. Sumber data terdiri dari data primer dan sekunder. Data primer diperoleh melalui observasi, wawancara langsung maupun dengan kuisoner. Data sekunder berupa dokumen atau data-data internal Direktorat Sumber Daya Manusia IPB seperti jumlah PLP dan tingkat jabatannya, jumlah Laboratorium, data peralatan dan bahan serta data-data lainnya yang mendukung penelitian ini.

Pemilihan nara sumber untuk data primer bersifat purposive sampling, sebagai mana di ungkap Satori dan Komariah (2011:50), bahwa penentuan sumber data pada penelitian kualitatif dilakukan secara purposive, yaitu ditentukan dengan menyesuaikan pada tujuan penelitian atau tujuan tertentu. Sumber yang akan diwawancara secara langsung adalah mereka yang memiliki pengetahuan, pengalaman dan terlibat langsung dalam pengelolaan laboratorium dan SDM didalamnya, yaitu ketua departemen, ketua divisi, kepala laboratorium dan pranata laboratorium pendidikan. Metode pengumpulan 
data dalam penelitian ini adalah observasi, wawancara, dokumentasi dan triangulasi (gabungan).

\section{Analisis data}

Analisis data secara kualitatif dengan menggunakan metode Interaktif Miles dan Huberman (1992), yang terdiri dari tiga alur kegiatan yaitu reduksi data, penyjajian data dan penarikan kesimpulan/verifikasi. Analisis kualitatif yang dilakukan didukung oleh data kuatitaif melalui data dianalisis dengan cara analisis ragam (ANOVA) dan rancangan yag digunakan yaitu Rancangan Acak Lengkap (RAL) nilai yang dipertoleh selanjutnya dilakukan antilon (anti-ln/ $\mathrm{e}^{\text {nilai }}{ }^{\mathrm{y}}$ ), maka akan mucul rataan geometrik kemudian dianalisis secara deskriptif kualitatif dan perumusan strategi dengan menggunakan matrik SWOT. Observasi yang dilakukan bersifat partisitif pasif. Wawancara langsung dilakukan semiterstruktur dengan menyiapkan pedoman wawancara tetapi berusaha menggali permasalahan secara terbuka.

Data yang sudah diperoleh kemudian dianalisis dengan mengunakan ragam (ANOVA) Rancangan Acak Lengkap (RAL) selanjutnya nilai yang peroleh dilakukan antilon (anti-ln/ $\left.\mathrm{e}^{\text {nilai }}{ }^{\mathrm{y}}\right)$, dan akan muncul rataan geometrik, curahan waktu PLP dalam kegiatan pendidikan/praktikum, penelitian dan pengabdian pada masyarakat, sedangkan kesenjangan jumlah PLP riil dan ideal menggunakan rumus formasi yang telah ada dalam PERMENPANRB No. 03 tahun 2010.

Strategi dirumuskan melalui analisis terhadap beberapa alternatif strategi yang sudah dimasukan pada matriks SWOT. Analisis ini didasarkan pada logika yang dapat memaksimalkan kekuatan dan peluang, namun secara bersamaan meminimalkan kelemahan dan ancaman. Strategi disesuaikan dengan faktor strategi internal dan eksternal dalam pengelolaan laboratorium serta PLP di IPB.

\section{HASIL DAN PEMBAHASAN Bidang Pendidikan/Praktikum}

Kuesioner mengacu pada butiran kegiatan PLP yang terdapat dalam lampiran PERMENPAN No. 03 tahun 2010, yaitu kegiatan yang harus dilakukan oleh setiap tingkat jabatan PLP yang berlainan yang merupakan kegiatan yang tridarma perguruan tinggi meliputi Pendidikan, Penelitian dan PPM. Berdasarkan kuesioner dapat dilihat efektivitas kegiatan PLP dalam hal aktivitas dan waktu yang digunakan dalam beraktivitas, pada setiap tingkat jabatan PLP yang ada di IPB. Rekaman kegiatan bidang pendidikan (Tabel 1), menunjukkan level aktivitas setiap tingkat jabatan sangat berbeda nyata, yang dinyatakan dalam nilai rataan geometrik yaitu pelaksana (2.92A), lanjutan (2.55B), penyelia (2.20C), pertama (1.26E), dan muda (1.47D). Sedangkan curahan waktu harian semester ganjil dan genap, yaitu pelaksana $(1.34 \mathrm{~B} ; 1.30 \mathrm{BC})$, lanjutan $(1.52 \mathrm{~B} ; 1.54 \mathrm{~B})$, penyelia $(1.20 \mathrm{~B} ; 0.89 \mathrm{C})$, pertama $(1.84 \mathrm{~B} ; 1.70 \mathrm{~B})$, dan muda $(3.78 \mathrm{~A}$; $4.14 \mathrm{~A})$.

Tabel 1 Kegiatan PLP bidang pendidikan (nilai rataan geometrik) 


\begin{tabular}{llccccc}
\hline \multirow{2}{*}{ No } & Peubah Pengamatan & \multicolumn{5}{c}{ Tingkat Kemampuan PLP (In) } \\
\cline { 2 - 6 } & Semester ganjil & Pelaksana & Lanjutan & Penyelia & Pertama & Muda \\
\hline & Level Aktivitas & $2.92 \mathrm{~A}$ & $2.55 \mathrm{~B}$ & $2.20 \mathrm{C}$ & $1.26 \mathrm{E}$ & $1.27 \mathrm{D}$ \\
2 & Curahan Waktu & & & & & \\
& a. Semester & $93.96 \mathrm{~B}$ & $107.01 \mathrm{~B}$ & $84.17 \mathrm{~B}$ & $128.13 \mathrm{~B}$ & $266.01 \mathrm{~A}$ \\
& $\quad$ b. 14 Pertemuan & $6.69 \mathrm{~B}$ & $7.62 \mathrm{~B}$ & $6.00 \mathrm{~B}$ & $9.13 \mathrm{~B}$ & $18.95 \mathrm{~A}$ \\
& $\quad$ c. Harian & $1.34 \mathrm{~B}$ & $1.52 \mathrm{~B}$ & $1.20 \mathrm{~B}$ & $1.84 \mathrm{~B}$ & $3.78 \mathrm{~A}$ \\
& Semester Genap & & & & & \\
1 & Level Aktivitas & $2.89 \mathrm{~A}$ & $2.53 \mathrm{~B}$ & $2.19 \mathrm{C}$ & $1.27 \mathrm{E}$ & $1.61 \mathrm{D}$ \\
2 & Curahan Waktu & & & & & \\
& a. Semester & $91.18 \mathrm{BC}$ & $108.09 \mathrm{~B}$ & $2.19 \mathrm{C}$ & $1.27 \mathrm{E}$ & $1.61 \mathrm{D}$ \\
& b. 14 Pertemuan & $6.90 \mathrm{BC}$ & $7.70 \mathrm{~B}$ & $4.44 \mathrm{C}$ & $8.51 \mathrm{~B}$ & $20.74 \mathrm{~A}$ \\
& c. Harian & $1.30 \mathrm{BC}$ & $1.54 \mathrm{~B}$ & $0.89 \mathrm{C}$ & $1.70 \mathrm{~B}$ & $4.14 \mathrm{~A}$ \\
\hline
\end{tabular}

Setiap pekerjaan yang dilakukan oleh PLP di IPB, setiap harinya dalam setiap semester yang dilakukan dengan kisaran 1-4 jam, PLP dalam melakukan pekerjaannya masih tergantung intruksi atasan atau belum adanya kemandirian. Hal ini merupakan akibat dari masih melekatnya tradisi lama di IPB, bahwa pekerjaan PLP adalah pekerjaan yang hanya menunggu instruksi dari atasan langsung. PLP sejak tahun 2010 sudah ditetapkan sebagai PNS yang mempunyai jabatan tertentu yaitu jabatan fungsional sesuai dengan PERMENPAN No.03 tahun 2010. Kemandirian PLP dalam pekerjaannya, meliputi tridarma perguruan tinggi (Pendidikan/Praktikum, Penelitian dan PPM), khususnya dalam pengelolaan dan pengembangan laboratorium.

Curahan waktu yang kecil pada jabatan terampil karena kegiatan yang dilakukan banyak yang sifatnya menyiapkan, membersihkan dan menata baik peralatan dengan kategori 1 dan 2 dengan bahan umum yang tidak memerlukan waktu yang lama dalam setiap kegiatan pendidikan/praktikum, terlebih pada kegiatan praktikum yang dilakukan dalam satu semesternya tidak penuh 14 pertemuan. Sebaliknya, PLP ahli memerlukan curahan waktu lebih lama, artinya semakin tinggi tingkat jabatannya, maka kemandirian dalam hal bekerja makin baik, Hal ini dapat dilihat pada curahan waktu bidang pendidikan pada Tabel 1.

\section{Bidang Penelitian}

Kegiatan bidang penelitian yang di lakukan PLP, yaitu berupa kegiatan pelayanan dalam penelitian mahasiswa dan dosen. Sama halnya pada bidang pendidikan, pada bidang penelitian juga terlihat curahan waktu yang di perlukan PLP ahli lebih banyak di bandingkan PLP terampil (Tabel 2). Hal ini juga berarti bahwa PLP terampil dalam kesehariannya bekerja, masih tergantung instruksi atasan (belum mandiri).

Tabel 2 Kegiatan PLP bidang penelitian (nilai rataan geometrik)

\begin{tabular}{llllll}
\hline \multirow{2}{*}{ No } & \multirow{2}{*}{ Peubah Pengamatan } & \multicolumn{4}{c}{ Tingkat Kemampuan PLP (In) } \\
\cline { 2 - 5 } & Pelaksana & Lanjutan & Penyelia & Pertama & Muda \\
\hline & Semester ganjil & & & &
\end{tabular}




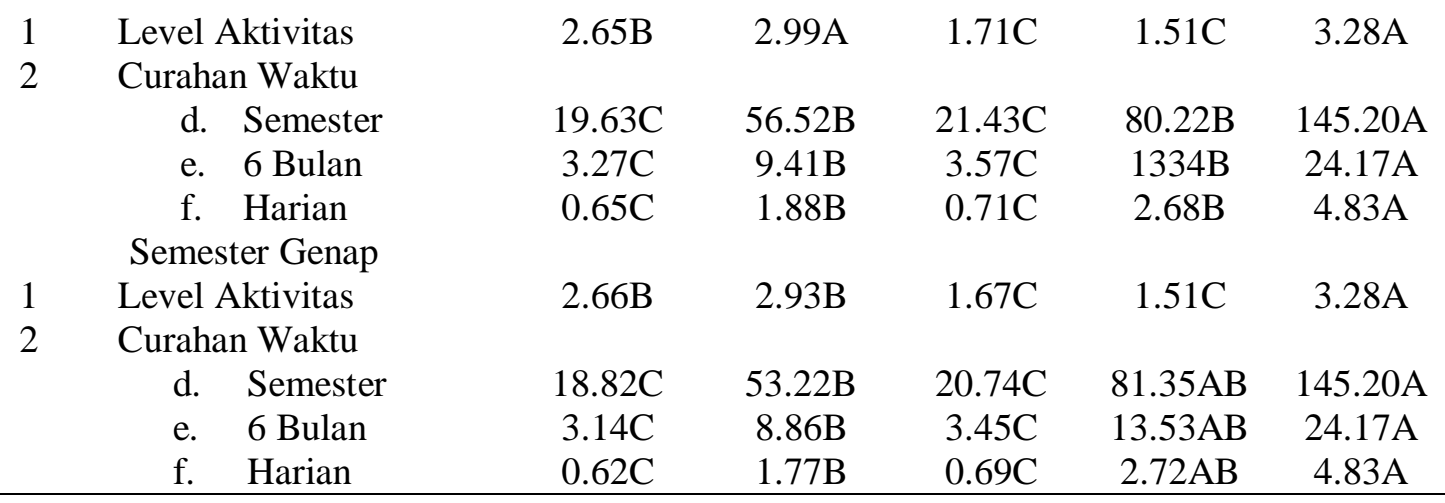

\section{Bidang PPM}

PLP belum banyak terlibat dalam kegiatan bidang PPM karena hanya pada laboratorium-laboratorium tertentu saja kegiatan ini berlangsung. Kegiatan PLP merupakan kegiatan rutin, karena sebagian besar dari laboratorium yang ada di IPB adalah laboratorium yang melayani pendidikan, dalam hal ini praktikum dan pelayanan penelitian tugas akhir mahasiswa dan dosen. Pada Tabel 3 dapat dilihat bahwa curahan waktu yang dilakukan pada PPM tidak terlalu banyak.

Tabel 3 Kegiatan PLP bidang PPM (nilai rataan geometrik)

\begin{tabular}{|c|c|c|c|c|c|c|}
\hline \multirow{2}{*}{ No } & \multirow{2}{*}{ Peubah Pengamatan } & \multicolumn{5}{|c|}{ Tingkat Kemampuan PLP (In) } \\
\hline & & Pelaksana & Lanjutan & Penyelia & Pertama & Muda \\
\hline & Semester ganjil & & & & & \\
\hline 1 & Level Aktivitas & $2.24 \mathrm{~A}$ & $2.59 \mathrm{~A}$ & $1.46 \mathrm{~B}$ & $1.43 \mathrm{~B}$ & $\begin{array}{c}1.54 \\
\mathrm{~B}\end{array}$ \\
\hline 2 & $\begin{array}{l}\text { Curahan Waktu } \\
\text { g. Semester }\end{array}$ & $18.71 \mathrm{~A}$ & $33.69 \mathrm{~A}$ & $2.22 \mathrm{~A}$ & $21.35 \mathrm{~B}$ & $\begin{array}{c}5.06 \\
\mathrm{R}\end{array}$ \\
\hline & h. $30 \mathrm{Jam}$ & $1.12 \mathrm{~A}$ & $0.62 \mathrm{~A}$ & $0.74 \mathrm{~A}$ & $0.71 \mathrm{~B}$ & 0.17 \\
\hline & i. Harian & $0.12 \mathrm{~A}$ & $0.22 \mathrm{~A}$ & $0.15 \mathrm{~A}$ & $0.15 \mathrm{~B}$ & $\begin{array}{c}0.03 \\
\mathrm{~B}\end{array}$ \\
\hline 1 & $\begin{array}{l}\text { Semester Genap } \\
\text { Level Aktivitas }\end{array}$ & $2.58 \mathrm{~A}$ & $2.60 \mathrm{~A}$ & $1.46 \mathrm{~B}$ & $1.43 \mathrm{~B}$ & $\begin{array}{c}1.54 \\
\text { B }\end{array}$ \\
\hline 2 & $\begin{array}{l}\text { Curahan Waktu } \\
\text { g. Semester }\end{array}$ & $17.49 \mathrm{~A}$ & $33.56 \mathrm{~A}$ & $21.41 \mathrm{~A}$ & $21.35 \mathrm{~A}$ & $\begin{array}{c}5.06 \\
B\end{array}$ \\
\hline & h. $30 \mathrm{Jam}$ & $0.58 \mathrm{~A}$ & $1.12 \mathrm{~A}$ & $0.71 \mathrm{~A}$ & $0.71 \mathrm{~A}$ & $\begin{array}{c}0.17 \\
\mathrm{~B}\end{array}$ \\
\hline & i. Harian & $0.11 \mathrm{~A}$ & $0.22 \mathrm{~A}$ & $0.14 \mathrm{~A}$ & $0.15 \mathrm{~A}$ & $\begin{array}{c}0.03 \\
\mathrm{~B}\end{array}$ \\
\hline
\end{tabular}

Dari hasil pemetaan kondisi aktual laboratorium di IPB, terlihat bahwa tipe laboratorium dapat dikategorikan tipe III, dilihat dari struktur organisasinya, laboratorium

Eko Prasetyo, M Syamsul Maarif, dan Komar Sutriah 
berada dibawah kebijakan departemen/jurusan, seperti yang diamanatkan oleh PERMENPAN\&RB No. 03 tahun 2010. Pada setiap laboratorium di IPB, keberadaan peralatan sebagai fasilitas penunjang tidak sesuai dengan acuan PERMENPAN\&RB, karena hampir sebagian besar dari laboratorium fisik belum melakukan penentuan kategori alat 1,2 dan 3, demikian pula dengan bahan yang ada di laboratorium. Untuk itu, diperlukan kebijakan dari pimpinan untuk menentukan tipe Semua ini dilakukan untuk memaksimalkan kualitas laboratorium serta kualitas pelayanan terhadap mahasiswa dan dosen.

Berdasarkan data didapatkan PLP terampil dan ahli menurut PERMENPAN\&RB, kemudian data diolah dengan menggunakan Uji-T berpasangan dengan perlakuan ideal dan riil dan mengunakan ulangan fakultas dan unit IPB pusat (Lab.Terpadu dan LPPM). Pada Tabel 4. dapat dilihat kesenjangan jumlah PLP IPB dengan jumlah PLP menurut PERMENPAN\&RB. Dalam PERMENPAN\&RB No. 03 tahun 2010, untuk Laboratorium Tipe III, formasi PLP tingkat terampil paling banyak 4 orang dan PLP tingkat ahli paling banyak 2 orang.

Tabel 4 Kesenjangan jumlah PLP IPB dengan jumlah PLP menurut PERMENPAN\&RB .

\begin{tabular}{|c|c|c|c|c|c|c|c|c|c|c|c|c|c|c|}
\hline \multirow[t]{2}{*}{$\begin{array}{l}\mathbf{N} \\
\mathbf{0}\end{array}$} & \multirow[t]{2}{*}{$\begin{array}{c}\text { Fakulta } \\
\text { s }\end{array}$} & \multicolumn{2}{|c|}{$\begin{array}{c}\text { Jml PLP } \\
\text { IPB } \\
\text { Tahun }\end{array}$} & \multicolumn{2}{|c|}{$\begin{array}{c}\text { Jml Lab } \\
\text { IPB } \\
\text { Tahun }\end{array}$} & \multicolumn{3}{|c|}{ Tipe Lab } & \multicolumn{2}{|c|}{$\begin{array}{c}\text { Jml PLP } \\
\text { menurut } \\
\text { Permenp } \\
\text { an-RB }\end{array}$} & \multicolumn{2}{|c|}{$\begin{array}{c}\text { Jml PLP } \\
\text { IPB }\end{array}$} & \multicolumn{2}{|c|}{ GAP } \\
\hline & & ' 11 & '15 & '11 & '15 & 12 & 3 & 4 & $\begin{array}{l}\text { Tr } \\
\text { pl }\end{array}$ & $\begin{array}{l}\text { Ahl } \\
\text { i }\end{array}$ & $\begin{array}{l}\text { Tr } \\
\text { pl }\end{array}$ & $\begin{array}{l}\text { Ahl } \\
\text { i }\end{array}$ & $\begin{array}{l}\text { Tr } \\
\text { pl }\end{array}$ & $\begin{array}{l}\text { Ahl } \\
\text { i }\end{array}$ \\
\hline 1 & FAPER & & & & & & 1 & & & & & & & \\
\hline & TA & 21 & 17 & 16 & 16 & & 6 & & 64 & 32 & 15 & 2 & 49 & 30 \\
\hline 2 & FKH & 32 & 28 & 25 & 9 & & 9 & & 36 & 18 & 22 & 6 & 14 & 12 \\
\hline 3 & FPIK & & & & & & 2 & & & & & & & \\
\hline 4 & FAPET & 23 & 21 & 12 & 24 & & $\begin{array}{l}4 \\
1\end{array}$ & & 96 & 48 & 11 & 10 & 85 & 38 \\
\hline 5 & FAHUT & 25 & 21 & 18 & 15 & & $\begin{array}{l}5 \\
3\end{array}$ & & 60 & 30 & 14 & 7 & 46 & 23 \\
\hline 6 & $\begin{array}{l}\text { AN } \\
\text { Fateta }\end{array}$ & 12 & 11 & 11 & 30 & & $\begin{array}{l}0 \\
4\end{array}$ & & 120 & 60 & 8 & 3 & 112 & 57 \\
\hline 7 & FMIPA & 20 & 19 & 15 & 44 & & $\begin{array}{l}4 \\
2\end{array}$ & & 176 & 88 & 16 & 3 & 160 & 85 \\
\hline & & 24 & 21 & 15 & 28 & & 8 & & 112 & 56 & 19 & 2 & 93 & 54 \\
\hline $\begin{array}{l}8 \\
9\end{array}$ & $\begin{array}{l}\text { FEMA } \\
\text { TERPA }\end{array}$ & 4 & 3 & 4 & 7 & & 7 & & 28 & 14 & 2 & 1 & 26 & 13 \\
\hline 1 & $\begin{array}{l}\text { DU } \\
\text { LPPM }\end{array}$ & 5 & 5 & 1 & 1 & & 1 & 1 & 0 & 4 & 3 & 2 & -3 & 2 \\
\hline 0 & & 15 & 15 & 4 & 13 & & 3 & & 52 & 26 & 14 & 1 & 38 & 25 \\
\hline
\end{tabular}

Eko Prasetyo, M Syamsul Maarif, dan Komar Sutriah 


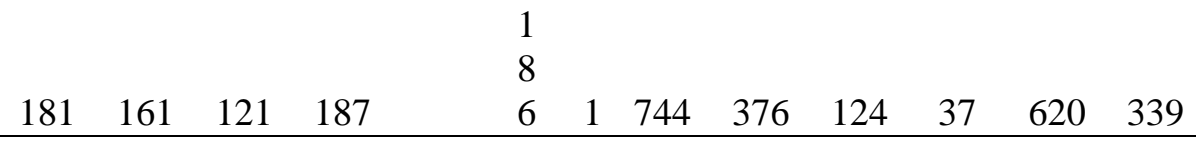

Perbedaan rataan jumlah PLP yang begitu besar antara keadaan riil dan menurut acuan PERMENPAN\&RB juga dapat dilihat pada Tabel 4. Perbedaan tersebut dapat disinergikan dengan curahan waktu pekerjaan PLP. Dengan data ini direktorat SDM harus melakukan evaluasi diri laboratorium terhadap laboratorium-laboratorium yang ada di lingkungan IPB.

Tabel 5 Matriks IFE Laboratorium di IPB

\begin{tabular}{|c|c|c|c|}
\hline FAKTOR INTERNAL & Bobot & Rating & Skor \\
\hline \multicolumn{4}{|l|}{ Kekuatan } \\
\hline A. Jumlah PLP banyak. & 0,143 & 4 & 0,500 \\
\hline B. Jumlah laboratorium banyak & 0,125 & 4 & 0,438 \\
\hline C. Adanya payung hukumdanperaturan & 0,125 & 4 & 0,500 \\
\hline $\begin{array}{l}\text { D. Bukti komitmen pimpinan IPB untuk } \\
\text { menerapkan PERMENPAN\&RB No.03 th } \\
2010\end{array}$ & 0,149 & 4 & 0,595 \\
\hline \multicolumn{4}{|l|}{ Kelemahan } \\
\hline $\begin{array}{l}\text { E. Peralatan dan bahan belum merata di setiap } \\
\text { laboratorium yang berdasar kriteria } \\
\text { PERMENPAN\&RB }\end{array}$ & 0,155 & 2 & 0,232 \\
\hline $\begin{array}{l}\text { F. Belum adanya kebijakan institusi atau } \\
\text { peraturan menteri mengenai peningkatan } \\
\text { kualitas dari PLP dengan beasiswa }\end{array}$ & 0,143 & 1 & 0,143 \\
\hline $\begin{array}{l}\text { G. Kurangmya respon PLP terhadap penerapan } \\
\text { PERMENPAN\&RB mengenai jabatan } \\
\text { fungsional PLP }\end{array}$ & 0,161 & 1 & 0,161 \\
\hline TOTAL & 1,000 & & 2,568 \\
\hline
\end{tabular}

Matriks EFE laboratorium di IPB dapat dilihat pada Tabel 5. Dari hasil analisis perhitungan faktor strategi eksternal didapat total skor sebesar 2,288. Nilai ini berada dibawah rataan sebesar 2,50, ini berarti menunjukan laboratorium di IPB belum dapat memanfaatkan peluang untuk mengatasi ancaman/pengaruh negatif eksternal, oleh karena itu memerlukan strategi yang lebih efektif untuk mengatasi faktor-faktor strategi eksternal laboratorium di IPB

Penentuan posisi strategi mkatriks IE didasarkan pada hasil total nilai matriks IFE yang diberi bobot pada sumbu x dan total nilai EFE pada sumbu y. Total nilai matriks 2,568 dan nilai matriks EFE 2,288. Dengan demikian posisi laboratorium di IPB terletak pada sel V, tetapi karena nilai matriks EFE berada dibawah rataan sebesar 2,50 maka strategi yang diterapkan adalah bagaimana pengelolaan laboratorium di IPB dalam mengatasi ancaman/pengaruh negatif eksternal. Hasil Identifikasi dari kekuatan, peluang dan ancaman laboratorium di IPB serta posisi yang berada pada sel V selanjutnya akan digunakan untuk merumuskan alternatif strategi dengan menggunakan matriks SWOT.

Eko Prasetyo, M Syamsul Maarif, dan Komar Sutriah 
Posisi laboratorium di IPB berdasarkan matriks IE dapat dilihat pada Gambar 2.

Tabel 6 Matriks EFE Laboratorium di IPB

\begin{tabular}{lccc}
\hline FAKTOR EKSTERNAL & Bobot & Rating & Skor \\
\hline Peluang & & & \\
A. Banyaknya jumlah kegiatan mahasiswa dan & 0,150 & 3 & 0,375 \\
$\begin{array}{l}\text { dosen dalam menggunakan laboratorium } \\
\text { Banyaknya jumlah peralatan dan bahan yang }\end{array}$ & 0,175 & 2 & 0,350 \\
$\begin{array}{l}\text { ada di laboratorium } \\
\text { Cetak IPB yang dekat dengan pembuat } \\
\text { kebijakan. }\end{array}$ & 0,250 & 2 & 0,500 \\
$\begin{array}{l}\text { Ancaman } \\
\begin{array}{l}\text { D. Peraturan pemerintah yang sewaktu-waktu } \\
\text { berubah. }\end{array}\end{array}$ & 0,225 & 3 & 0,563 \\
E. Persaingan global yang semakin dekat. & 0,200 & 3 & 0,500 \\
\hline TOTAL & 1,000 & & 2,288 \\
\hline
\end{tabular}

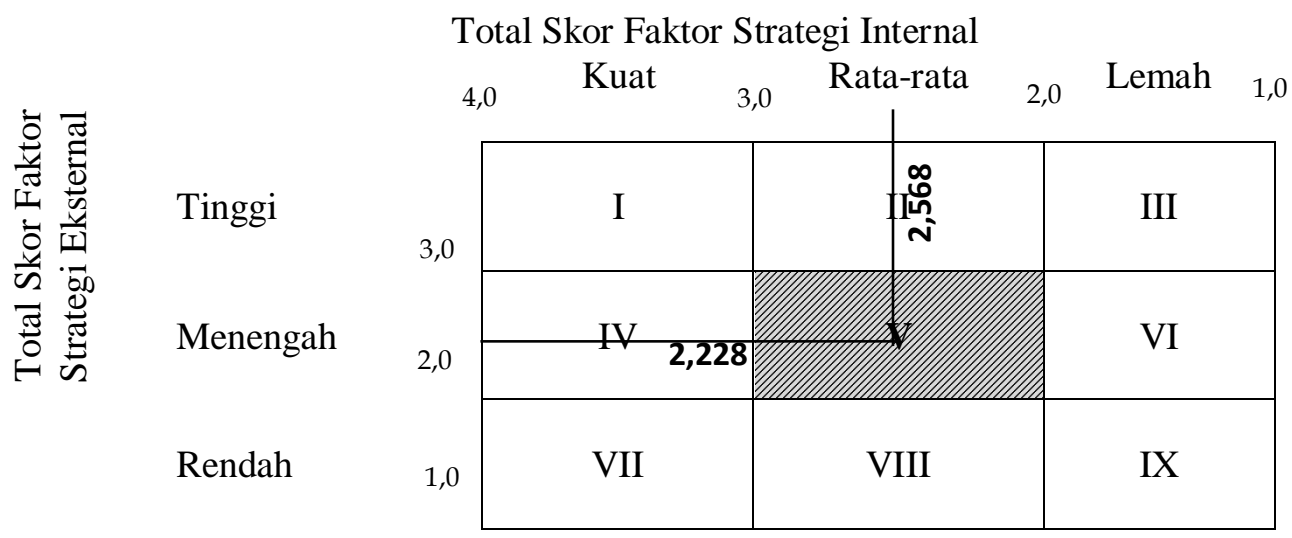

Gambar 2. Matriks IE Laboratorium di IPB

Hasil identifikasi dan diskusi dengan beberapa pakar dan pengambil kebijakan di IPB yang telah dilakukan untuk mengembangkan matriks SWOT adalah sebagai berikut:

\section{Identifikasi Kekuatan}

Jumlah PLP dan laboratorium yang dimiliki banyak, yaitu 161 orang dan 187 laboratorium. Jumlah ini belum berimbang dengan jumlah laboratorium yang ada, akan tetapi pimpinan dapat melakukan evaluasi diri laboratorium, agar dengan jumlah yang ada dapat memaksimalkan pengelolaan laboratorium.

Adanya payung hukum dan peraturan pemerintah untuk menerapkan jabatan fungsional pada PLP. Landasan hukum merupakan peraturan baku sebagai tempat berpijak atau titik tolak dalam melaksanakan kegiatan-kegiatan tertentu, yaitu peran serta PLP dalam kegiatan pendidikan di lembaga pendidikan tinggi.

Komitmen pimpinan IPB untuk menerapkan PERMENPAN\&RB No 03 tahun 2010 sehingga PLP dapat melaksanakan tugasnya dengan baik. Komitmen sangat dibutuhkan untuk membangun hubungan antar pekerja dan antara pekerja dengan

Eko Prasetyo, M Syamsul Maarif, dan Komar Sutriah 
atasannya, untuk menciptakan iklim kerja yang kondusif dan memberikan tanggung jawab yang jelas Gaspersz (2002).

\section{Identifikasi Kelemahan}

Peralatan dan bahan belum merata di setiap laboratorium berdasarkan kriteria PERMENPAN\&RB. Kriterian laboratorium tipe III harus memenuhi persyaratan adanya peralatan kategori 1,2 dan 3 serta bahan umum dan bahan khusus (PERMENPAN\&RB No. 03 tahun 2010). Pelatihan dan pengembangan keterampilan (trainning and skill development) merupakan suatu bagian yang integral dari sistem kerja yang paling baru atau merupakan komitment yang lebih besar terhadap pentingnya pelatihan dan pengembangan SDM (Ellitan 2002).

Kurangnya respon PLP terhadap penerapan jabatan fungsional sehingga masih banyak PLP yang belum dapat naik pangkat sesuai ketentuan yang berlaku. Peran SDM dalam mensosialisasikan peraturan ini harus terus dilakukan, baik pada tingkat kepala laboratorium, pimpinan departemen dan fakultas, serta pimpinan pusat.

\section{Identifikasi Peluang}

Banyaknya jumlah kegiatan mahasiswa dan dosen dalam menggunakan laboratorium baik untuk praktikum ataupun penelitian. Aktivitas praktikum mahasiswa serta penelitian mahasiswa dan dosen yang sering dilakukan di laboratorium akan membuat PLP lebih mudah mendapatkan angka kredit yang dapat berdampak pada ketepatan waktu kenaikan pangkat.

Banyaknya jumlah peralatan dan bahan yang ada dilaboratorium. Jumlah peralatan dan bahan yang ada dilaboratorium juga menentukan aktivitas dari kegiatan PLP di laboratorium yang akan berdampak terhadap kecepatan pengumpulan angka kredit kenaikan pangkat dan jabatan.

Letak IPB yang dekat dengan pembuat kebijakan. Hal ini akan mempercepat dan memudahkan bila terdapat informasi yang sangat pentinng. Kedudukan informasi dalam suatu organisasi digambarkan dengan sangat tepat oleh Moerdick et al. (1982) sebagai aliran darah dalam tubuh manusia, analogi ini memperlihatkan betapa pentingnya informasi bagi kehidupan organisasi, karena dengan informasi kita mampu meraih peluang lebih banyak, muncul kesempatan baru yang layak untuk dicoba.

\section{Identifikasi Ancaman}

Peraturan pemerintah yang sewaktu-waktu dapat berubah. Perubahan memiliki efek psikologis yang sangat besar kepada pikiran manusia. Perubahan bisa menjadi ancaman apabila segala hal menjadi lebih buruk, yang akan mengakibatkan tujuan dari organisasi tidak menuju ke arah yang positif.

Persaingan global yang semakin ketat antar universitas yang ada di regional ataupun internasional. Kualitas SDM harus ditingkatkan baik secara formal maupun informal. 
Tabel 7 Matriks SWOT PLP IPB

\begin{tabular}{|c|c|c|}
\hline Faktor Eksternal & $\begin{array}{ll} & \text { Kekuatan (S) } \\
\text { 1. Jumlah PLP banyak } \\
\text { 2. Jumlah } \\
\text { laboratorium } \\
\text { banyak. } \\
\text { 3. Adanya payung } \\
\text { hukum dan } \\
\text { peraturan } \\
\text { 4. Bukti komitmen } \\
\text { pimpinan IPB untuk } \\
\text { menerapkan } \\
\text { PERMENPAN\&R } \\
\text { B No.03 th 2010 }\end{array}$ & 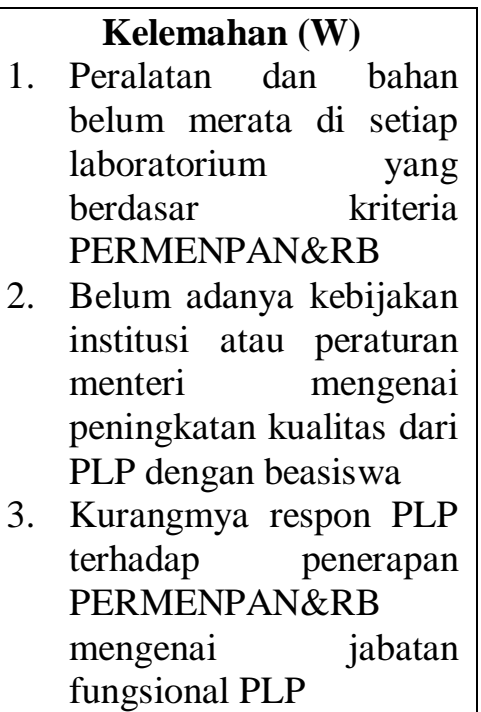 \\
\hline Peluang (O) & Strategi S-O & egi W-O \\
\hline 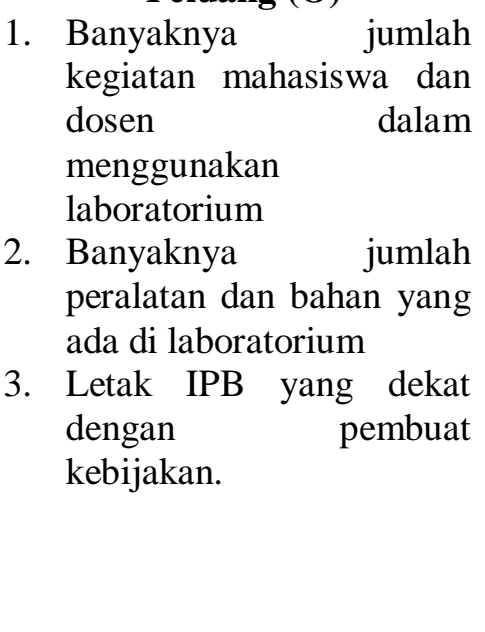 & 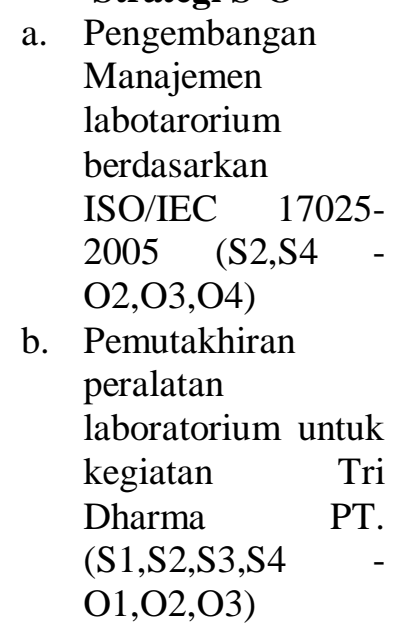 & $\begin{array}{l}\text { a. Menyediakan peralatan } \\
\text { dan bahan yang sesuai } \\
\text { kebutuhan laboratorium } \\
\text { berdasar r pada } \\
\text { PERMENPAN\&RB. )S1, } \\
\text { S2,S3- O1,O2,O3) } \\
\text { b. Meningkatkan kinerja } \\
\text { PLP. (S1, S2,S3 - } \\
\text { O1,O2,O3) }\end{array}$ \\
\hline Ancaman (T) & Strategi S-T & Strategi W-T \\
\hline $\begin{array}{l}\text { 1. Peraturan pemerintah } \\
\text { yang sewaktu-waktu } \\
\text { berubah. } \\
\text { 2. Persaingan global yang } \\
\text { semakin dekat. }\end{array}$ & $\begin{array}{l}\text { a. Memperbaiki gaya } \\
\text { kepemimpinan (S3, } \\
\mathrm{S} 4-\mathrm{T} 1, \mathrm{~T} 2)\end{array}$ & $\begin{array}{l}\text { a. Mengembangkan } \\
\text { kapabilitas SDM PLP } \\
\text { yang akan berdampak } \\
\text { pada pengembangan } \\
\text { laboratorium r yang } \\
\text { diharapkan. (S1,S2,S3- } \\
\text { T1, T2). }\end{array}$ \\
\hline
\end{tabular}

Keterangan: - (Si:Oi) atau (Si:Ti) atau (Wi:Oi) atau Wi:Ti) menunjukkan kombinasi lingkungan eksternal dengan internal dalam menghasilkan pilihan strategi

$$
\text { - } \quad \mathrm{i}=1,2, \ldots . \mathrm{n}
$$

Berdasarkan matriks SWOT dapat dirumuskan beberapa alternatif strategi peningkatan kualitas kerja PLP di IPB yaitu: 
Pengembangan Manajemen labotarorium berdasarkan ISO/IEC 17025-2005 (S2,S4 - O2,03,04), Laboratorium merupakan tempat bagi Mahasiswa untuk melatih diri dalam pengembangan kemampuan dari materi yang didapat dari teori. Kondisi laboratorium merupakan faktor yang sangat penting dalam pelaksanaan praktikum pada ruangan laboratorium. Menanggapi masalah diatas, salah satu standar sistem manajemen mutu laboratorium yang telah diterapkan pada laboratorium-laboratorium di negara maju dan bahkan di negara-negara berkembang adalah ISO/IEC 17025: 2005. Standar ini digunakan oleh laboratorium untuk mengembangkan sistem manajemen mutu, administratif, dan kegiatan teknis laboratorium.

Pemutakhiran peralatan laboratorium untuk kegiatan Tri Dharma PT. (S1,S2,S3,S4 - O1,O2,O3). Peralatan laboratorium adalah sebuah pendukung dalam kegiatan didalam sebuah laboratorium sebagaimana disebutkan pada PERMENPAN\&RB No. 03 tahun 2010. Peralatan laboratorium yang selanjutnya disebut peralatan adalah mesin, perkakas, perlengkapan, dan alat-alat kerja lain yang secara khusus dipergunakan untuk pengujian, kalibrasi, dan/atau produksi dalam skala terbatas.

Memperbaiki gaya kepemimpinan (S1, S2, S3 - T1, T2). Memperbaiki gaya kepemimpinan merupakan salah satu alternatif strategi yang dapat meminimalkan ancaman yang ada pada PLP dengan menggunakan kekuatan yang dimiliki. Gaya kepemimpinan adalah perilaku dan strategi, sebagai hasil kombinasi dari falsafah, keterampilan, sifat, sikap, yang sering diterapkan seorang pemimpin ketika ia mencoba mempengaruhi kinerja bawahannya (Tampubolon 2007).

Menyediakan peralatan dan bahan yang sesuai kebutuhan laboratorium berdasar pada PERMENPAN\&RB (W1, W3 - O1, O2, O3). Untuk memberikan pelayanan laboratorium yang berorientasi kepada kepuasan pelanggan, maka strategi menyediakan peralatan dan bahan yang sesuai kebutuhan laboratorium, merupakan strategi yang harus di implementasikan oleh IPB pada laboratorium-laboratorium yang dimilikinya. Berkaitan dengan kualitas pelayanan, Gronroos (1990) mendefinisikan pelayanan (service) sebagai suatu aktivitas atau rangkaian aktivitas dimana terjadi interaksi dengan seseorang atau mesin secara fisik sebagai penyediaan kepuasan pelanggan.

Meningkatkan kinerja PLP (W1, W2, W3 - 01, O2, O3). Strategi meningkatkan kinerja PLP memerlukan respon pimpinan terhadap aturan PERMENPAN\&RB secara menyeluruh. Banyaknya kegiatan praktikum dan penelitian harus ditunjang oleh peralatan dan bahan yang tersedia, sehingga memudahkan PLP untuk naik pangkat. Hakim (2006) mendefinisikan kinerja sebagai hasil kerja yang dicapai oleh individu, yang disesuaikan dengan peran atau tugas individu tersebut dalam suatu perusahaan pada suatu periode waktu tertentu, yang dihubungkan dengan suatu ukuran nilai atau standar tertentu dari perusahaan dimana individu tersebut bekerja.

Mengembangkan kapabilitas SDM PLP yang akan berdampak pada pengembangan laboratorium yang diharapkan (W1, W2, W3 - T1, T2). Peningkatan kualitas SDM laboratorium akan berdampak pada peningkatan kualitas layanan dan kualitas mahasiswa/lulusan.. Hasibuan (1994) juga mengemukakan pentingnya 
pengembangan SDM, sebagai upaya mencapai tujuan organisasi, tujuan karir dan tujuan nonkarir, yang dapat ditempuh melalui pelatihan.

\section{SIMPULAN}

Kondisi aktual beban kerja yang dilakukan PLP menyatakan kurangnya curahan waktu yang dilakukan untuk setiap tingkat jabatan PLP. Hal ini sebagai indikator bahwa tingkat kinerja dari PLP masih berdasar instruksi dari atasan langsung dan belum bekerja secara mandiri, Kondisi yang ada juga menggambarkan belum tersosialisasinya PERMENPAN\&RB ini dengan baik.

Perhitungan formasi dalam PERMENPAN\&RB tersebut adalah perhitungan statistik nasional yang telah dilakukan uji petik kebutuhan SDM laboratorium dan kegiatannya. Keadaan ini disebabkan sebagian besar pimpinan unit/kepala laboratorium belum mengetahui adanya PERMENPAN\&RB , sedangkan hal yang sangat penting terkait pengelolaan laboratorium dan PLP ada didalam peraturan tersebut.

Pentingnya penerapan manajeman laboratorium yang baik yaitu satu standar sistem manajemen mutu laboratorium yang harus diterapkan pada laboratorium di IPB sebagai strategi memanfaatkan peluang untuk mengatasi ancaman/pengaruh negatif eksternal laboratorium di IPB.

\section{DAFTAR PUSTAKA}

Aranya N, Ferris KR. 1984. Recxamination of accountan organizational profesional conflict. The Accounting Review. 59(1): 1-12.

Ellitan L. 2002. Praktik-praktik sumber daya manusia dan keunggulan kompetitif berkelanjutan. Jurnal Manajemen \& Kewirausahaan. 4(2): 65-76.

Gronroos C. 1990. Service Management and Marketing. Toronto (US): Lexington Books.

Hasibuan M. 1994. Manajemen Sumber Daya Manusia. Jakarta (ID): Haji Masagung.

Hakim A. 2006. Analisis pengaruh motivasi, komitmen organisasi dan iklim organisasi terhadap kinerja pegawai pada dinas perhubungan dan telekomunikasi Provinsi Jawa Tengah. JRBI. 2(2): 165-180.

Irawan P. 2004. Logika dan Prosedur Penelitian. Jakarta (ID): STIA-LAN.

[IPB] Institut Pertanian Bogor. 2012. Rencana Strategis Sumberdaya Manusia IPB, Menuju Perguruan Tinggi Berbasis Riset Kelas Dunia. Bogor (ID): Direktorat SDM IPB.

[IPB] Institut Pertanian Bogor. Rencana Strategis IPB 20014-2018. http://www.ipb.ac.id. [10 Januari 2016].

ISO/IEC 170256:2005 Standar Internasional, Persyaratan Umum Kompetensi Laboratorium Pengujian dan Laboratorium Kalibrasi, Versi Bahasa Indonesia, edisi kedua .

[Kemendiknas] Kementerian Pendidikan Nasional. 2010. Peraturan Menteri Negara Pendayagunaan Aparatur Negara dan Reformasi Birokrasi No. 03/Januari/2010 dan Peraturan Bersama Menteri Pendidikan Nasional dan Kepala Badan Kepegawaian Negara No. 02/V/PB/2010 dan No. 13/Mei/2010, Tentang Petunjuk Pelaksanaan Jabatan Fungsional Pranata Laboratorium Pendidikan dan Angka Kreditnya. Jakarta (ID): Kemendiknas.

[Kemristekdikti] Kementerian Riset Teknologi dan Pendidikan Tinggi 2015. Peraturan Menteri Riset Teknologi dan Pendidikan Tinggi Nomor 44 Tahun 2015. Tentang

Eko Prasetyo, M Syamsul Maarif, dan Komar Sutriah 
Standar Nasional Pendidikan Tinggi. [diunduh tanggal 20 januari 2016]. Tersedia pada : https://www.Permenristekdikti 2015.

Miles H, Huberman A M. 1992. Analisis Data Kualitatif. Terjemahan Tjetjep Rohendi R. Universitas Indonesia Press. Jakarta

Satori D. \& Komariah A. 2011. Metode Penelitian Kualitatif. Alfabeta: Bandung

Sutriah K. 2011. Sosialisasi dan Workshop Jabatan PLP di Lingkungan Institut Pertanian Bogor, Bogor (ID): Direktorat SDM IPB.

Tampubolon BD. 2007. Analisis faktor gaya kepemimpinan dan faktor etos kerja terhadap kinerja pegawai pada organisasi yang telah menerapkan SNI 19-90012001. Jurnal Standardisasi. Volume 9 (2) :106-115. 